\title{
Relative Effectiveness of Energy Efficiency Programs versus Market Based Climate Policies in the Chemical Industry
}

\author{
by
}

\author{
Gale A. Boyd \\ Duke University
}

\author{
Jonathan M. Lee \\ East Carolina University
}

\section{CES 18-16 April, 2018}

The research program of the Center for Economic Studies (CES) produces a wide range of economic analyses to improve the statistical programs of the U.S. Census Bureau. Many of these analyses take the form of CES research papers. The papers have not undergone the review accorded Census Bureau publications and no endorsement should be inferred. Any opinions and conclusions expressed herein are those of the author(s) and do not necessarily represent the views of the U.S. Census Bureau. All results have been reviewed to ensure that no confidential information is disclosed. Republication in whole or part must be cleared with the authors.

To obtain information about the series, see www.census.gov/ces or contact Christopher Goetz, Editor, Discussion Papers, U.S. Census Bureau, Center for Economic Studies 5K028B, 4600 Silver Hill Road, Washington, DC 20233, CES.Working.Papers@census.gov. To subscribe to the series, please click here. 


\begin{abstract}
This paper addresses the relative effectiveness of market vs program based climate policies. We compute the carbon price resulting in an equivalent reduction in energy from programs that eliminate the efficiency gap. A reduced-form stochastic frontier energy demand analysis of plant level electricity and fuel data, from energy-intensive chemical sectors, jointly estimates the distribution of energy efficiency and underlying price elasticities. The analysis controls for plant level price endogeneity and heterogeneity to obtain a decomposition of efficiency into persistent (PE) and time-varying (TVE) components. Total inefficiency is relatively small and price elasticities are relatively high. If all plants performed at the 90th percentile of their efficiency distribution, the reduction in energy is between $4 \%$ and $13 \%$. A modest carbon price of between $\$ 9.48 /$ ton and $\$ 14.01 /$ ton CO2 would achieve reductions in energy use equivalent to all manufacturing plants making improvements to close the efficiency gap.
\end{abstract}

Keyword: Energy efficiency, price elasticities, manufacturing, stochastic frontier, plant-level data

\footnotetext{
* This paper was funded by the U.S. Energy Information Administration (EIA), Office of Energy Consumption and Efficiency Analysis while working with Leidos Inc. under contract with EIA (DE-EI0000564) and was prepared while the authors were Special Sworn Status researchers at the Triangle Research Data Center, a member of the Federal Statistical Research Data Center Network. The paper benefited from ongoing discussions and comments from Kelly Perl and Paul Otis on an earlier draft. Any opinions and conclusions expressed herein are those of the author(s) and do not necessarily represent the views of the U.S. Census Bureau or EIA. All results have been reviewed to ensure that no confidential information is disclosed.
} 


\section{Introduction}

The Paris Accord has a goal of reducing $\mathrm{CO}_{2}$ emissions to limit climate change to less than 2 degrees $C$. It has been broadly embraced by nearly every nation of the world. Even in the United States, where the Trump administration has stated its intent to pull out of the accord in 2020 and cancel the Clean Power Plan, climate policy is still being pursued by regions, states, cities, and via other existing programs at the Federal level. One might argue that the success of the Paris Accord is that it is not prescriptive regarding the types of policies nations must pursue, much the same way that a variety of policies are being pursued in the US, irrespective of the accord.

The policy options available to reduce $\mathrm{CO}_{2}$ emissions are as varied as the sources of $\mathrm{CO}_{2}$ themselves; de-carbonization energy use and reducing total energy demand are the overarching goals. The policy levers can range from market approaches, e.g. carbon taxes or tradeable permits, to prescriptive regulations, e.g. renewable portfolio standards or fuel economy / equipment standards, to voluntary programs, e.g. informational and behavior based interventions. Economists often point out the benefits of market approaches, while others may point to market failures as justifications for the latter form of policies and programs. Market approaches rely on the price responsiveness of the demand sector to generate change in the level or mix of energy use. One important way that policies and programs work is to reduce existing inefficiencies that may not be responsive to price changes, per se. The relative effectiveness of market (price) vs policy/programs (efficiency) will depend on the energy price elasticities of demand vis-à-vis the extent of existing levels of (in)efficiency. Sectors with high price elasticity and low levels of efficiency gap would be best tackled with market approaches; policies and programs would be more effective in sectors with the opposite, low elasticities and high levels of energy efficiency gap.

The energy efficiency gap has been the subject of numerous studies (Jaffe and Stavins 1994, Huntington 1995, Allcott and Greenstone 2012, Boyd and Zhang 2013, Boyd and Curtis 2014, Boyd 2016) but few look at simultaneous price and efficiency effects.

This paper addresses this empirical question with an industry case study of energy intensive chemical manufacturing in the U.S. Using stochastic frontier analysis (SFA) on the most detailed, plant-level data available, this paper econometrically

1) estimates the persistent and time varying energy efficiency gap while accounting for both industry-sector specific and plant level heterogeneity

2) estimates energy price elasticities while accounting for energy price endogeneity

A two stage SFA is applied to estimate energy demand frontiers for electricity and fuel separately for 4 segments of the industry. This provides an estimate of the possible demand response to market based policies as well a programs designed to close the efficiency gap. While the cost-effectiveness of such programs are not considered, they are assumed to be limited by the estimated, pre-existing efficiency levels. We then compute the carbon price that would be needed to reduce demand by the same amount that is implied by the estimates of the 
energy efficiency gap. This price provides a metric to compare the two sources of carbon reductions.

The importance of the industrial sector in terms of energy demand can't be overstated. In the U.S. 2017 Annual Energy outlook (U.S. Energy Information Administration 2017), industrial is the only sector that energy use is forecast to grow; residential, commercial, and transportation energy consumption are flat. This does not mean that industry doesn't respond to prices or experience technical change. While these types of improvements in efficiency occur in all sectors, improvements in the industrial sector do not keep pace with economic growth. It may even be the case that policies and programs in the non-industry sectors are easier to implement, e.g. CAFÉ standards in transport or appliance \& lighting standards in residential and commercial sectors, and are responsible for the improvements in energy efficiency that have led to declining or stable demand. Regardless, it is likely that potential impact of energy policies and programs targeted at the industrial sector will be limited to reducing levels of current inefficiency, at least in the near term. The relative size of efficiency vs price response will be key to determining what policies are likely to be more impactful.

This paper provides estimates of energy efficiency and energy price response in the energy intensive chemical manufacturing sector and shares important features with the methodology presented in and applied to analyze metal based durables (Boyd and Lee 2016) in that it measures the distribution of energy efficiency of demand relative to local (plant level) energy prices. This paper uses a two stage variant of SFA that allows us to account for both plant level energy price endogeneity and plant specific heterogeneity in energy use. For a review of endogeneity in SFA see (Amsler, Prokhorov et al. 2016). This paper takes a slightly different approach because we are concerned with both price endogeneity and systematic plant level heterogeneity in energy use. The two stage method developed by (Kumbhakar, Lien et al. 2014) and modified here to account for plant level price endogeneity controls for both. This modification is an important contribution to the literature. The two stage approach also allows the decomposition of efficiency into a plant specific (persistent) and time-varying components, which can be compared across new and continuing plants. This is another contribution to the literature to explore the dynamic aspects of efficiency.

Jointly estimating the plant level price response and efficiency gap is important. For example, (Gerarden, Newell et al. 2017) point out that divergence of plant level price from average prices may overstate engineering estimates of the efficiency gap. From the perspective of applying SFA or its non-parametric counterpart, Data Envelopment Analysis (DEA), to energy efficiency whether the efficiency measure is viewed as a purely technical efficiency or includes allocative efficiency depends on the inclusion of the relevant prices. (Filippini and Hunt 2015) discuss the difference in the treatment of technical and allocative efficiency in more detail. (Boyd and Lee 2016) observe that including prices in their model can be motivated by a directional distance function. (Chung, Fare et al. 1997) introduce the directional distance function in the context of desirable and undesirable outputs; the energy sub-vector (directional) distance function as defined by (Boyd 2008) presents this approach as a measure of energy efficiency.

Figure 1 illustrates the production isoquant for energy and all other quasi-fixed inputs and fixed output; the interior point $A$ to the isoquant is inefficient. The difference between the energy 
sub-vector (directional) distance function, AC, where the pure technical efficiency gap is measured as a reduction in energy use, holding other quasi-fixed inputs and production constant and one that includes both technical and allocative efficiency is embodied in the direction that efficiency is measured depending on prices. In this example, when one accounts for energy prices the efficiency gap is lower than when considering pure technical efficiency. In figure 1 at "high" relative energy prices the optimal energy use is $E_{1}{ }^{*}$ and the gap is $E_{-} E_{1}{ }^{*}$. In the presence of lower relative energy the level of the efficiency gap is smaller, $\mathrm{E}_{-} \mathrm{E}_{2}{ }^{*}$. We wish to estimate the plant level distribution of the efficiency gap, using local energy prices, and also the price responsiveness represented by the own price elasticity.

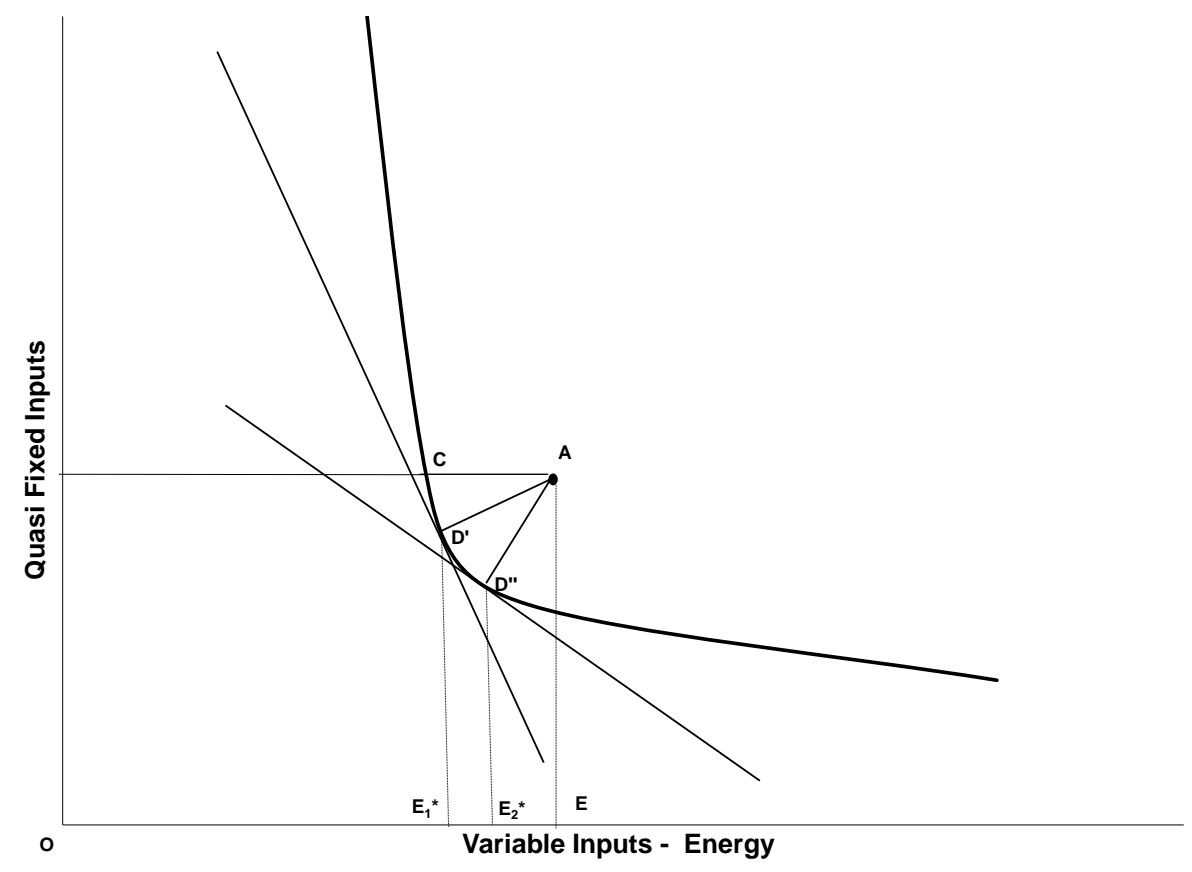

Figure 1 Comparison of Optimal Price Direction Distance Functions

Similarly, failure to account for sector and plant heterogeneity may also be sources of error in the efficiency gap estimation. We use detailed plant level data and disaggregate the analysis into of 6 digit NAICS codes. This accounts for sector level heterogeneity in both the price and efficiency estimates. In addition, as described below, there is good reason to consider additional, within-sector, plant level heterogeneity. We model this using the two stage SFA. The advantage of this approach is that the possibility of price endogeneity is treated in the first stage of the two step process.

We conduct a parallel analysis of two different sources of plant level data, as detailed below, since these data sources each have both advantages and disadvantages (see data section for overview). The use of these plant level data sources is another contribution to the literature. To our knowledge few, if any, studies of industrial energy demand and efficiency use plant level data. The closest we are aware of is (Bostian, Färe et al. 2016, Lundgren, Marklund et al. 2016, Zhang, Lundgren et al. 2016, Lundgren and Zhou 2017) all of which use SFA on the same firm level data for Swedish manufacturing; (Lutz, Massier et al. 2017) using SFA on German firm level 
data. (Nguyen and Streitwieser 2008) (Bardazzi, Oropallo et al. 2015) estimate production functions from which price elasticities can be derived, but not energy efficiencies, using U.S. plant and Italian firm level data.

Once the estimates are obtained we conduct a simple policy exercise to compare the effectiveness of market vs efficiency programs for climate policy. We compute the carbon price that will reduce energy consumption by an amount equivalent to closing the energy efficiency gap at a level of performance equal to the $90^{\text {th }}$ percentile of the estimated efficiency distribution. This is the final result and contribution of the paper.

This paper is organized as follows. The first sections provide an overview of energy intensive chemical manufacturing and describe the two plant level data sources at the core of the analysis. The next sections describe concerns over plant level energy price endogeneity and plant specific heterogeneity. A two - stage approach is presented as a solution. This section also introduces the notion of time-varying and persistent inefficiency. The parameter estimates for the elasticities and the distribution(s) for efficiency are presented for both data sources and for the logit fuel share analysis that is conditional on a level of energy demand. Finally, the price (carbon or energy tax, etc.) that would be required to reduce energy demand, equivalent to the estimated levels of efficiency is computed. This provides a basis for comparison of possible relative effectiveness of market based or program based climate policy.

\section{Background on the U.S. Chemical Industry}

The Chemical Industry, as defined by the North American Industry Classification System (NAICS) code 325 , is a diverse collection of sectors ranging from commodity chemicals (e.g. ammonia, chlor-alkalies, ethylene) to consumer products (e.g. paint, pharmaceuticals, cosmetics, etc.) The former are the up-stream process industries that encompass some of the most energyintensive, chemical conversions of feedstock into intermediate chemicals, which are used primarily by other industries. The latter uses and produces a wide range of downstream chemicals to make, package and distribute final consumer goods. Of the over 5 Quads ${ }^{2}$ of energy reported by the 2010 Manufacturing Energy Consumption Survey (MECS) that is used in NAICS 325, about 4.2 are used in the 13 energy intensive 6-digit NAICS listed below.

These energy intensive chemical sectors can be grouped into four chemical industry classifications that mimic the 4-digit NAICS hierarchical groups with some minor exceptions; Inorganic Chemicals, Organic Chemicals, Plastics and Resins, and Fertilizers. This is the same industry sector grouping used by the National Energy Modeling System (NEMS) Industrial Demand Module (IDM) (Energy Information Administration 1994).

$\underline{\text { Inorganic Chemicals }}$

- 325120

- 325181

- 325182
Industrial Gases

Alkalies and Chlorine

Carbon Black

\footnotetext{
2 This 5 quads includes feedstocks as well as energy for heat and power. All energy data are from the 2010 MECS Table 1.2 First Use of Energy for All Purposes (Fuel and Nonfuel). These data are measured at end-use; i.e. electric generation losses are not included.
} 
- 325188

Other Basic Inorganic Chemicals

Organic Chemicals

- 325110

Petrochemicals

- 325192

Cyclic Crudes and Intermediates

- 325193

Ethyl Alcohol

- 325199

Other Basic Organic Chemicals

Plastics and Resins

- 325211

Plastics Materials and Resins

- 325212

Synthetic Rubber

- 325222

Noncellulosic Organic Fibers

$\underline{\text { Fertilizers }}$

- 325311

Nitrogenous Fertilizers

- 325312

Phosphatic Fertilizers

This disaggregation of the chemical industry is important to more closely align the production activities into more homogenous groups for the purpose of energy analysis, as has been done in the NEMS model. However, even within these groups and associated 6-digit NAICS codes there is heterogeneity of energy use. For example, the primary chemical conversion in NAICS 325311 - Nitrogenous Fertilizers is from a feedstock, typically natural gas, to ammonia. Ammonia production is the most energy intensive step in the chain of nitrogen based fertilizer products. Ammonia is produced in a small number of plants and then used by other plants in the industry to manufacture other fertilizer products (Kermeli, Worrell et al. 2017). Ammonia may also be produced as an intermediate product in fully integrated production facilities. At the plant level there will be substantial differences in energy intensity even within this "narrowly defined" sector. There are similar examples in both organic chemicals and plastics \& resins, where ethylene is the energy intensive primary chemical for a wide range of products. While the downstream products may also be energy intensive compared to other manufacturing, ethylene is much more so (Neelis, Worrell et al. 2008).

\section{Data}

Data for the study are non-public plant-level Census Bureau data available in the Federal Statistical Research Data Center. These data are protected under Title 13 and 26 of the US Code and used with permission from the Bureau. Since these sectors are energy intensive, a parallel approach regarding the data sources is used. These data sources are the Manufacturing Energy Consumption Survey (MECS) and the quinquennial Census of Manufacturing (CM). MECS is a sample based survey conducted in 1985, 1988, 1991, 1994, $1998,2002,2006$, and $2010^{3}$. The CM is part of the quinquennial Economic Census (EC); in principle it includes all establishments operating during the analysis time period of 5 five-year

\footnotetext{
${ }^{3} 2014$ was the most recent year, but not yet available to external researchers.
} 
time steps, 1992, 1997, 2002, 2007, and 2012. Both data span similar time periods but, for the most part, different years. The MECS and CM each have advantages and disadvantages which is why a parallel analysis approach was used.

Data needed for the analysis include energy use and prices along with production activities and other location specific variables. While the Manufacturing Energy Consumption Survey (MECS) provides the most detailed data on energy use, particularly cost and quantity of fuels by type, the MECS is a stratified sample and not a balanced panel so the presence (absence) of an observation is not an indicator of entry (exit) in the industry. We need this information on entry/exit/continuing status for the relative efficiency of entering vs continuing plants. Using the Census of Manufacturing (CM), part of the quinquennial Economic Census (EC) solves this problem.

The availability of plant level electricity use and prices in the $\mathrm{CM}$ is one advantage of this data set. The CM provides plant level electricity consumption and costs, from which a plant level average price can be computed directly. (Davis, Grim et al. 2012) analyze the dispersion of those prices in detail. However, the $\mathrm{CM}$ only reports cost of fuels, not quantities, so Btu fuel consumption is imputed from fuel costs in the $\mathrm{CM}$ assuming state level average price of fossil fuels. In analysis by (Boyd and Lee 2017) fossil fuel use imputed from the price of natural gas. This was seen as a reasonable assumption for the metal based durables industries, because publicly available MECS data from 2010 for these 5 sectors suggests that $88 \%$ to $98 \%$ of the purchased fuel in this sector is natural gas. This is less true for energy intensive chemicals. MECS reports that in 2010 natural gas was only $77 \%$ of fossil fuels used for heat and power in these energy intensive sectors. This study imputes Btu consumption by taking the cost of fuels and dividing by a weighted average of the state level fossil fuel prices as published by the EIA's State Energy Data System (SEDS) ${ }^{4}$, where the weights are computed from the published MECS data for each 6-digit NAICS above and applied to the closest year between the MECS and CM. Plants which generate part of their own electricity, not un-common in this industry, will likely purchase more fossil fuel and less electricity. To account for this the ratio of generated power to the total net consumption is computed.

Plant level shipment values, adjusted for inventory changes are used to measure production. Labor is measured in production worker hours. Capital stock is the total of plant and equipment. Non-energy material costs is computed by subtracting total material expenditures less cost for electricity and fuels. All data in $\$$ values are deflated using the (Bartelsman and Gray 1996) NBER 6-digit NAICS price deflators. The ZIP code location of the plant is merged with NOAA weather station data to get a plant specific heating and cooling degree day (HDD and $(D D)$ measure as a control for the energy impact of location and time specific climate conditions.

The MECS provides the most detailed data on energy use, particularly cost and quantity of fuels by type. The MECS is a sub-sample of the Census Bureau's Annual Survey of Manufactures

\footnotetext{
${ }^{4}$ SEDS data is available online at the following: http://www.eia.gov/state/seds/ (last accessed November, 2016).
} 
(ASM) that targets mainly large plants ${ }^{5}$. MECS provides detail on a wide range of fossil fuel types, including the quantity of fossil fuels used as feedstocks. The plant level cost and quantity can be used to compute plant level average fossil fuel prices, as well as plant level electricity prices. While the MECS is a sub-sample its primary advantage is in the fossil fuel detail; a major component of energy use in this industry. MECS data on fossil fuel consumption is obtained by directly aggregating over all fossil energy types, excluding those used as feedstocks ${ }^{6}$. Costs are similarly aggregated and plant level average fuel prices are constructed and deflated to constant dollars using a GDP price deflator. MECS also indicates the amount of fossil fuels, mostly natural gas and gas liquids, as chemical feedstocks. Since plants using these feedstocks are likely to be more energy intensive, an indicator variable is created to reflect a plant is a feedstock using plant. All other economic variables in the MECS sample analysis are the same as those constructed for the CM.

\section{Methodology}

This section briefly presents the ad-hoc demand model specification. This is done by adding energy prices to the energy factor requirement function described by (Boyd and Delgado 2012), which is equivalent to a directional input distance function. (Boyd and Lee 2016) motivate this by considering the energy prices as a modification of the direction of the distance function, but do not make that connection explicit. A review of stochastic frontier applications for energy use can be found in (Filippini and Hunt 2015). The paper then discusses concerns regarding price endogeneity and plant level heterogeneity. A two stage estimation approach is presented as a solution that addresses both of these concerns in the first stage. This approach also allows for the decomposition of efficiency into two components; one is plant specific and constant over time (persistent efficiency) and one that is time varying.

\section{Stochastic Frontier approach to Energy demand}

Following (Boyd and Lee 2016) we specify an SF ad hoc energy demand equation for the two primary energy types in each of the four sectors, with a few modifications, which are discussed below. We consider log linear models (KLEM Cobb-Douglas) of the general form,

$\ln E_{j, i, t}=f\left(\ln Y_{i, t}, \ln K_{i, t}, \operatorname{lnEmp} p_{i, t}, \operatorname{lnNEM_{i,t}}, \ln P_{j, t, s}\right.$, DYear $_{t}$, DNAICS $\left._{k}, G E R A T I O_{i, t}\right)+\varepsilon_{j, i, t}$

(1)

Where

$\ln E_{j, i, t} \quad=\quad \log$ of energy use

$\ln Y_{i, t} \quad=\quad \log$ of production or output

$\operatorname{lnEmp}_{i, t} \quad=\quad \log$ employment or other measure of labor

\footnotetext{
${ }^{5}$ In later years of the MECS the sample design is not strictly a sub-sample of the ASM, but we need data from the ASM on production and employment, so in those years we use the overlap between MECS and ASM.

${ }^{6}$ Data from the $\mathrm{CM}$ on fuel use states that this is for heat and power and should not include feedstocks, making these definitions comparable.
} 


\begin{tabular}{|c|c|c|}
\hline $\ln K_{i, t}$ & $=$ & log capital stock \\
\hline $\ln N E M_{i, t}$ & $=$ & log of non-energy material use \\
\hline $\ln P_{j, t, s}$ & $=$ & In price of energy ${ }^{7}$ \\
\hline DYear & $=$ & dummy for the year \\
\hline$D N A I C S_{k}$ & $=$ & dummy for the 6-digit NAICS code \\
\hline$G E R A T I O_{i, t}$ & $=$ & ratio of self generated electricity to total purchased + generated - sold \\
\hline \multicolumn{3}{|c|}{$\mathrm{j}$ = energy type (electricity and fuel) } \\
\hline \multicolumn{3}{|c|}{$\mathrm{i}=$ individual establishment (i.e. manufacturing plant) } \\
\hline \multicolumn{3}{|l|}{ s = state } \\
\hline \multicolumn{3}{|c|}{$t=$ year of the observations i.e. 1992, 1997, 2002, 2007, and 2012} \\
\hline $\mathrm{k}=6$-digit $\mathrm{N}$ & & \\
\hline
\end{tabular}

The standard SF approach is to treat $\varepsilon_{j, i, t}$ as the sum two terms representing statistical noise, $v_{j, i, t}$, and inefficiency, $u_{j, i, t}$, respectively. We will return to specific approaches to the distributional assumptions of $\varepsilon_{j, i, t}$ below.

Total value of shipments (TVS), deflated and adjusted for inventory changes is used as the measure of productive output. Labor, measured by number of employees, controls for plant level utilization effects ${ }^{8}$, since labor may be sticky in the short run. To better control for upstream and downstream plants within the sectors we include capital stock and non-energy materials. The most energy intensive chemical processes tend to be very capital intensive and have very simple material feedstocks. Downstream plants may purchase chemicals produced by upstream plants and may involve simpler, less energy intensive production processes. ${ }^{9}$ To account for this we consider non-energy material use. Non-energy material use, is the deflated costs of material purchases, less energy costs, which are included in the Census (material costs variables. The long run relationship between energy and plant scale is captured by the combined coefficient on production, capital, non-energy materials and labor. In a simple CobbDouglas specification the sum of the coefficients reflect the economies of scale with respect to energy. If the sum of the coefficients is less than one then we can infer that larger plants will have lower frontier energy intensity than smaller plants. This means that the model will control for scale differences with respect to the energy efficiency measure.

Even within our 4 chemical sectors there can be a lot of heterogeneity of products and corresponding energy services, so 6 digit NAICS industry controls (industry fixed effects) are

\footnotetext{
7 The subscript 's' refers to state level, but we use both state and plant level prices as detailed below.

${ }^{8}$ Using the 5-year Economic Census also conveniently avoids the years of the Great Recession by including 2007 and 2012, but not the intervening years.

${ }^{9}$ We estimate models with and without capital stock (see appendix for results excluding capital stock), because the capital stock variable is not available in our final CM year, 2012.
} 
used in the empirical analyses. One could consider 10 digit product level dummies as well, since the CM has such detail. (Boyd 2016) reviews industry specific case studies of energy use that employ some of this finer product detail. However, doing so would require very specific prior information about which product level NAICS are more/less intensive, since there are a very large number of 10-digit product NAICS. We believe that the 6 digit controls are sufficient and are more detailed than other industrial energy studies have employed before. One exception is (Boyd and Curtis 2014) who also use plant level Census micro-data at the 6-digit level.

The price variables, $\ln P_{j, t, s}$, reflects the impact of the prices of both electricity and natural gas on the frontier level of energy use. Incorporating prices into the factor requirement function allows us to measure price responsiveness of the sectors. If we view the model in a production function context then higher energy prices could act as an exogenous shifter of the frontier, i.e. induced technical change. The prices of both types of energy ( $j=$ electricity and fuel) may impact either energy type. Variation in energy prices can be used to capture price incentives and allocative efficiency. Electricity and fuel have different data issues in the $\mathrm{CM}$, so the treatment of prices is different for the alternative energy sources. Specifically, Census data collects plant level cost and quantity for electricity but only costs for fossil fuels. The problem with using plant level electric prices ${ }^{10}$ directly in the model is that the plant may have some bargaining power or simply more choice over rate plans, with larger electricity users realizing lower average prices, resulting in an endogenous variable.

We considered the possibility that Heating Degree Days (HDD) and Cooling Degree Days (CDD) could be used to control for ambient weather conditions on an annual basis using the zip-code location of the plant. Weather can impact building heating, ventilation and air-conditioning (HVAC) energy use, but also impact process energy via outside air to ovens and furnaces or chiller efficiencies, to the extent that the production requires these process. Preliminary analysis found these to be insignificant predictors of energy use with negligible impacts on plant efficiency. This is not surprising given the small role for HVAC in the chemical sector. As a result, these variable were excluded in the final model results.

Modeling electricity and fuel separately has advantages, since sector specific process needs will differ in terms of energy type. However, there may be opportunities to substitute electricity for fuel, combined heat and power (CHP) being the most obvious. Since Census data does include on-site generation we include a variable to control for this. We compute the ratio of selfgenerated power to the sum of self-generated power and purchased power minus sales to the grid and include it as a control variable. In the electric equation we would expect the generated electricity ratio coefficient to be negative (i.e. less purchased electricity), but in the fuel equation the coefficient would be positive account for the amount of extra fuel consumed in the CHP.

Directly estimating the model above faces some issues due to particular concerns in these sectors. These concerns are regarding endogeneity of energy prices and plant level

\footnotetext{
${ }^{10}$ These prices are not true marginal prices, but include demand charges, etc. They are total expenditures divided by total consumption.
} 
heterogeneity that should be separated from efficiency. The next two sections describe these concerns, followed by our approach to account for them.

\section{Price endogeneity}

Large energy users, either by virtue of sheer size or by virtue of having energy intensive production processes have good reasons to get the lowest possible energy prices. This means that lower plant level prices would be correlated with higher energy demand for reasons other than pure price responsiveness, i.e. estimated price elasticities would be biased upwards in absolute terms due to simultaneity bias. Preliminary analysis using plant level electricity prices from both the CM and MECS found extremely high own-price elasticities of demand and complementarity between fuel and electricity, i.e. negative cross-price elasticities in fossil fuel demand. The ability to explore endogeneity concerns were limited to electricity use in the CM analysis, which includes data on plant level electric use and price but not fuel prices. The MECS data analysis allow for analysis of both plant level electricity and fuel price endogeneity to be considered as well.

Concerns regarding and methods to control for endogeneity in the maximum likelihood SF context is reviewed by (Amsler, Prokhorov et al. 2016). One approach is the control function. In this method plant level energy prices are regressed against the instrument, in this case state level price, and all the independent variables of the SF model. The residuals of this first stage regression are included in the SF estimation. A significant coefficient on the residuals indicates the prices are endogenous. We take a slightly different approach. We employ instrumental variables estimators to instrument plant level prices with average state level industrial energy prices in the first stage of the two stage SFA. State level prices are published by the Energy Information Administration (EIA) State Energy Data System (SEDS). The advantage of these data is that they are collected consistently by EIA over the time period from surveys of the utility service companies. The average price charged to industrial consumers will account for both the cost structure of the utility, regional/temporal differences in utility regulation/restructuring, and the different rates structures available to all industrial consumers.

\section{Plant Heterogeneity}

Even within these 4 sectors of the chemical industry we anticipate plant level differences in processes and products that can require very different levels of energy. In organic chemicals the production of ethylene is much more energy intensive than subsequent downstream product. Ethylene is a component of many plastics, so if a plastics plant is fully integrated and produces its own ethylene then that plant would be much more energy intensive. Another example is ammonia production for fertilizers. This is a primary chemical input to other fertilizer chemical and is also produced as a final product. Ammonia production is a very energy intensive chemical to produce, but fertilizer plants may buy it instead of making it on site. There are other examples of producing sulphur related chemicals where the process is exothermic, i.e. since the reaction generates useable energy rather than requiring energy to sustain it.

One approach to account for plant heterogeneity would be use detailed material and product codes. This has been done by (Boyd and Delgado 2012, Boyd and Guo 2014, Boyd 2016) for 
some selected industries, but requires a large amount of knowledge regarding which specific material and product types are most relevant. Use of capital stock and material purchases might partially account for these plant level differences, since energy intensive plants are likely to have less expensive feedstocks since they may make, rather than buy some intermediate product. Making an intermediate product is more likely to be both more energy intensive and more capital intensive as well. Even though we include capital stock and material purchases in the specification, additional methods to account for plant level heterogeneity are desirable.

The desire to distinguish between efficiency and heterogeneity requires an extension of the SFA frame work to a panel-data setting. The standard treatment for plant level heterogeneity in panel data is to include either a plant specific fixed or random effect. Equation (2) represents the non-stochastic frontier implementation of plant level heterogeneity by the inclusion of $\omega_{i}$, for the $i^{\text {th }}$ plant. $\omega_{i}$, may be estimated by either a fixed or random effects estimator. In our application below we focus on results generated from a random effects estimator.

$$
E_{i, t}=f\left(X_{i, t}: \theta\right)+\omega_{i}+\varepsilon_{i, t}
$$

In the SF approach the typical error term is hypothesized to be made up of two parts,

$$
\varepsilon_{i, t}=u_{i, t}+v_{i, t}
$$

Where $u_{i, t}$ is a one-sided efficiency error term and $v_{i, t}$ is noise. (Greene 2002) shows that this extension of the SF framework is econometrically tractable via maximum likelihood estimation (MLE). This approach has been labeled Greene's true fixed effect (TFE) and true random effect (TRE) estimators. In the TRE model, the estimates of $\omega_{i}$ are the basis for an estimate of persistent efficiency and $u_{i, t}$ is time varying efficiency. (Filippini and Hunt 2011, Filippini and Hunt 2012) employ this approach on panels of US states and OECD countries, respectively. However, these models can be difficult to obtain convergence in the MLE when the number of time periods is relatively small and the number of plants is relatively large. This was the same problem reported by (Boyd and Lee 2016) and is the case here as well. In this case the smallest plant sample size was 300 (Fertilizers), with most being over 2000 . The number of time periods is five.

An alternative approach is to estimate these error components in a two stage process (Kumbhakar, Lien et al. 2014). The next section describes the two stage process. The advantages here is that the convergence problems are ameliorated and both heterogeneity and the price endogeneity is treated in the first stage using a random effects for heterogeneity and an instrumental variable approach for endogeneity.

\section{Two stage model for persistent and time varying efficiency}

The plant level efficiency estimates are obtained by a two stage approach. The first stage uses a plant level random effects estimator with state level electricity prices as an instrument for plant level electricity prices. The general form for the random effects estimate is

$$
E_{i, t}=f\left(X_{i, t}: \theta\right)+\omega_{i}+\varepsilon_{i, t}
$$


Where $\omega_{i}$ is the plant level random effect for the $\mathrm{i}^{\text {th }}$ plant and $\varepsilon_{i, t}$ is Gaussian error. These two error components are not directly observable, but the residual of the regression, $E_{i, t}-$ $f\left(X_{i, t}: \hat{\theta}\right)$, can be decomposed into an estimate of the plant specific effect, $\widehat{\omega_{l}}$ that is constant over time for each plant and the time varying noise component, $\widehat{\varepsilon_{l, t}}$, based on the estimated parameters, $\hat{\theta}$.

$$
\begin{aligned}
& \widehat{\omega_{l}}=E\left[\omega_{i}: E_{i, t}-f\left(X_{i, t}: \hat{\theta}\right), \hat{\theta}\right] \\
& \widehat{\varepsilon_{l, t}}=E\left[\varepsilon_{i, t}: E_{i, t}-f\left(X_{i, t}: \hat{\theta}\right), \hat{\theta}\right]
\end{aligned}
$$

The second stage is used to further extract efficiency estimates from the decomposed error terms using the stochastic frontier. Using the two plant level estimates from the first stage, a frontier analysis is conducted on each estimated error component

$$
\begin{aligned}
& \widehat{\omega_{\imath}}=\alpha+u_{i}^{p e r}+v_{i} \\
& \widehat{\varepsilon_{l, t}}=\alpha+u_{i, t}{ }^{t v}+v_{i, t}
\end{aligned}
$$

Where the "usual" stochastic frontier model assumptions apply; $u_{i}{ }^{p e r}$ and $u_{i, t}{ }^{\text {tv }}$ follow a onesided exponential distribution and $v_{i}$ and $v_{i, t}$ are noise. We are not interested in the estimate, $\hat{\alpha}$, per se, but in the estimates of $\widehat{u_{l, t} t v}$ and $\widehat{u_{l}{ }^{p e r}}$ based on the residuals, $\widehat{\omega_{l}}-\hat{\alpha}$ and $\widehat{\varepsilon_{l, t}}-\hat{\alpha}$, from each regression. The standard JMLS (Jondrow, Materov et al. 1982) frontier estimates from STATA of $\widehat{u_{l, t}{ }^{t v}}$ and $\widehat{u_{l}{ }^{p e r}}$ are obtained from these two $2^{\text {nd }}$ stage regressions. The exponent of these JMLS estimates represent time-varying (tv) and persistent (per) efficiency.

$$
\begin{gathered}
t v_{i, t}=\exp \left(\widehat{u_{l, t}^{t v}}\right), \quad(7 \mathrm{a}) \\
\operatorname{per}_{i}=\exp \left(\widehat{u_{l}^{p e r}}\right), \quad(7 \mathrm{~b}) \text { and } \\
\operatorname{tot}_{i, t}=\exp \left(\widehat{u_{l, t}^{t v}}+\widehat{u_{l}^{p e r}}\right)(7 \mathrm{c}) .
\end{gathered}
$$

Where tot $_{i, t}$ is the combined total efficiency estimate.

\section{Empirical Results}

The model and estimation approach described above is applied to a panel dataset for the CM and MECS in separate analysis. In principle, these data sets could be pooled, but we do separate analyses for two reasons. The first is that the MECS is a stratified sample (overrepresentative of energy intensive plants) and the $\mathrm{CM}$ is a Census, i.e. includes all plants. We wish to explore how these two data collections might impact the results. The second is that MECS has much more detail on energy, including physical measure of fossil fuels and the corresponding detail needed to compute fuel specific, plant-level prices. The detailed nature of the MECS also might result in different persons within a firm/plant to be tasked to fill out the survey form, compared to the CM. In some sense the MECS might include better or more accurate data on energy use, particularly with respect to fuels. While there are differences in the parameter estimates, the broad pattern of results, particularly for the efficiency measures, are similar. The summary section compares the stylized results from the two data sets. 
The next section presents the results from the $\mathrm{CM}$ analysis for each of the four sectors and two energy types. The impact of the instrumental variables on the price elasticities is discussed. The efficiency estimates are discussed in some detail, including the decomposition of efficiency into persistent and time varying and the comparison of efficiency for existing and new plants, i.e. whether new plants that enter the industry are more efficient than their counterparts. Finally we explore the aggregate implications for the estimated distribution of total efficiency in these sectors.

The subsequent sections highlight some differences that arise from using the MECS sample. These include the ability to instrument for fossil fuel prices using the same approach as employed in the CM dataset .

\section{Two Stage SFA Parameter Estimates - CM data}

In the first stage of the two-stage process the ad hoc energy demand model described in equations (1) and (2) using a random effects estimator for $\omega_{i}$, the plant level random effect for the $\mathrm{i}^{\text {th }}$ plant ${ }^{11}$. We instrument for endogeneity of plant level electricity prices using state level prices as reported in the EIA SEDS data.

Two sets of analysis were done; one includes capital stock and the other does not. Capital stock data is not available in the CM for 2012. Results for the models without capital stock, but including 2012, are included in the appendix. Estimates of the price elasticities and efficiency measure are very similar.

Tables 1-4 show the estimates for inorganic, organic, resins and plastics, and fertilizers, respectively, for each energy type. Results are for the random effects estimator (RE) and with and without the instrumental variables for Price (IV-RE) The use of instrumental variables for electricity price results in lower electric price elasticities in all four sectors, but still exhibit relatively high price elasticities, ranging from -0.75 to -1.3 . In three of the four sectors the use of instruments also eliminates the significant estimates of complementarity for electricity price in the fossil fuel equation. In two cases the coefficient of concern changes sign and in all cases the coefficient is no longer significant. Fossil fuel own-price elasticities are all greater than unity, ranging from -1.2 to -1.3 . For the most part there isn't significant evidence of substitution (significant cross price coefficients) between electricity and fuels. However, in Resins and Plastics there is significant complementarity of fossil fuels in the electric equation, but not the reverse.

Non-energy materials is significant in only one sector and for electricity use. Inorganic chemicals is a very diverse collection of products and processes, some of which are quite electric intensive. One is industrial gases. It may be that some plants in this sector primarily mix or bottle gases made elsewhere for delivery. If that is the case then those plants might have high non-energy material shares. Examining the micro data suggests that this was often the case; this sector had the highest level of variation in non-energy material shares. Even with

\footnotetext{
${ }^{11}$ A fixed effect first stage was also estimated, but those results are not presented here. The random effects stage one resulted in better convergence of the SF second stage, to the random effects estimator is our preferred approach.
} 
the 6-digit NAICS control we believe that the negative and significant coefficient reflects this underlying phenomenon.

The self-generation ratio is always significant and has the expected sign, positive for fuel and negative for electricity, with exception of fuel use in fertilizers. The mean time varying and persistent efficiencies are almost all above 0.8 and have very small standard deviations. Since total efficiency is the product of the two components the mean for total efficiency is smaller. We will take a closer look at the efficiency distribution, focusing on results from the IV model, the preferred specification. 
Table 1 Two Stage SFA Estimates for Inorganic Chemicals, by type of Energy, with and without price instrument - CM data

\begin{tabular}{|l|l|l|l|l|}
\hline VARIABLES & Electricity & Electricity & Fuels & Fuels \\
\hline $\ln E m p$ Log Employment & $0.0741^{*}$ & $0.0711^{*}$ & $0.314^{* * *}$ & $0.308^{* * *}$ \\
\hline $\ln K \quad$ Log Capital & $0.339^{* * *}$ & $0.347^{* * *}$ & $0.265^{* * *}$ & $0.275^{* * *}$ \\
\hline $\ln N E M$ Log non-energy Materials & $-0.318^{* * *}$ & $-0.323^{* * *}$ & 0.0442 & 0.0397 \\
\hline $\ln Y$ Log Total Value of Shipments & $0.899^{* * *}$ & $0.910^{* * *}$ & $0.417^{* * *}$ & $0.431^{* * *}$ \\
\hline GERATIO Self Generation Ratio & $-0.494^{* * *}$ & $-0.524^{* * *}$ & $2.086^{* * *}$ & $2.058^{* * *}$ \\
\hline $\ln P_{N G}$ Log Natural Gas Price & -0.0399 & -0.0690 & $-1.181^{* * *}$ & $-1.242^{* * *}$ \\
\hline $\ln P_{\text {Elec Log Electricity Price }}$ & $-1.271^{* * *}$ & $-1.098^{* * *}$ & -0.131 & 0.176 \\
\hline Constant & $-2.711^{* * *}$ & $-2.484^{* * *}$ & $3.649^{* * *}$ & $4.692^{* * *}$ \\
\hline & & & & \\
\hline Observations & 2400 & 2400 & 2400 & 2400 \\
\hline Number of Firms & 1400 & 1400 & 1400 & 1400 \\
\hline Model & $\mathrm{RE}$ & $\mathrm{IV}-\mathrm{RE}$ & $\mathrm{RE}$ & $\mathrm{IV}-\mathrm{RE}$ \\
\hline Time-varying Efficiency & 0.983 & 0.835 & 0.972 & 0.789 \\
\hline Std Dev & 0.0203 & 0.0448 & 0.0698 & 0.119 \\
\hline Persistent Efficiency & 0.980 & 0.971 & 0.975 & 0.951 \\
\hline Std Dev & 0.0405 & 0.0855 & 0.0707 & 0.0773 \\
\hline Overall Efficiency & 0.964 & 0.811 & 0.948 & 0.751 \\
\hline Std Dev & 0.0445 & 0.0790 & 0.0201 & 0.119 \\
\hline$* * * \mathrm{p}<0.01, * * \mathrm{p}<0.05, * \mathrm{p}<0.1$ & & & & \\
\hline
\end{tabular}

Table 2 Two Stage SFA Estimates for Organic Chemicals, by type of Energy, with and without price instrument

\begin{tabular}{|l|l|l|l|l|}
\hline VARIABLES & Electricity & Electricity & Fuels & Fuels \\
\hline $\ln E m p$ Log Employment & $0.306^{* * *}$ & $0.309^{* * *}$ & $0.153^{* * *}$ & $0.158^{* * *}$ \\
\hline $\ln K \quad$ Log Capital & $0.196^{* * *}$ & $0.200^{* * *}$ & $0.368^{* * *}$ & $0.377^{* * *}$ \\
\hline $\ln N E M$ Log non-energy Materials & -0.0207 & -0.0209 & 0.0298 & 0.0313 \\
\hline $\ln Y$ Log Total Value of Shipments & $0.652^{* * *}$ & $0.650^{* * *}$ & $0.483^{* * *}$ & $0.478^{* * *}$ \\
\hline GERATIO Self Generation Ratio & $-1.839^{* * *}$ & $-1.850^{* * *}$ & $1.006^{* * *}$ & $0.965^{* * *}$ \\
\hline $\ln P_{N G}$ Log Natural Gas Price & -0.0646 & -0.0841 & $-1.262^{* * *}$ & $-1.318^{* * *}$ \\
\hline $\ln P_{\text {Elec Log Electricity Price }}$ & $-0.973^{* * *}$ & $-0.917^{* * *}$ & $-0.405^{* * *}$ & -0.244 \\
\hline Constant & $-1.973^{* * *}$ & $-2.169^{* * *}$ & $3.503^{* * *}$ & $2.867^{* * *}$ \\
\hline & & & & \\
\hline Observations & 1900 & 1900 & 1900 & 1900 \\
\hline Number of Firms & 1100 & 1100 & 1100 & 1100 \\
\hline Model & $\mathrm{RE}$ & $\mathrm{IV}-\mathrm{RE}$ & $\mathrm{RE}$ & $\mathrm{IV-RE}$ \\
\hline Time-varying Efficiency & 0.865 & 0.859 & 0.980 & 0.807 \\
\hline Std Dev & 0.0710 & 0.0417 & 0.0990 & 0.0864 \\
\hline Persistent Efficiency & 0.843 & 0.833 & 0.969 & 0.965 \\
\hline Std Dev & 0.0514 & 0.0721 & 0.0971 & 0.0990 \\
\hline Overall Efficiency & 0.730 & 0.715 & 0.950 & 0.779 \\
\hline Std Dev & 0.0524 & 0.0695 & 0.000610 & 0.0660 \\
\hline$* * *$ p<0.01, ** $\mathrm{p}<0.05, * \mathrm{p}<0.1$ & & & & \\
\hline
\end{tabular}


Table 3 Two Stage SFA Estimates for Resins and Plastics, by type of Energy, with and without price instrument

\begin{tabular}{|l|l|l|l|l|}
\hline VARIABLES & Electricity & Electricity & Fuels & Fuels \\
\hline $\ln E m p$ Log Employment & $0.295^{* * *}$ & $0.296^{* * *}$ & -0.0428 & -0.0435 \\
\hline $\ln K \quad$ Log Capital & $0.254^{* * *}$ & $0.260^{* * *}$ & $0.356^{* * *}$ & $0.375^{* * *}$ \\
\hline $\ln N E M$ Log non-energy Materials & 0.0112 & 0.0250 & $0.0888^{*}$ & $0.132^{* * *}$ \\
\hline $\ln Y$ Log Total Value of Shipments & $0.534^{* * *}$ & $0.524^{* * *}$ & $0.559^{* * *}$ & $0.528^{* * *}$ \\
\hline GERATIO Self Generation Ratio & $-1.399^{* * *}$ & $-1.411^{* * *}$ & $2.177^{* * *}$ & $2.147^{* * *}$ \\
\hline $\ln P_{N G \text { Log Natural Gas Price }}$ & $-0.209^{* * *}$ & $-0.258^{* * *}$ & $-1.058^{* * *}$ & $-1.204^{* * *}$ \\
\hline $\ln P_{\text {Elec Log Electricity Price }}$ & $-0.922^{* * *}$ & $-0.754^{* * *}$ & $-0.326^{* * *}$ & 0.179 \\
\hline Constant & $-1.247^{* * *}$ & $-0.801^{* *}$ & $1.228^{* * *}$ & $2.558^{* * *}$ \\
\hline & & & & \\
\hline Observations & 2300 & 2300 & 2300 & 2300 \\
\hline Number of Firms & 1300 & 1300 & 1300 & 1300 \\
\hline Model & $\mathrm{RE}$ & $\mathrm{IV}-\mathrm{RE}$ & $\mathrm{RE}$ & $\mathrm{IV}-\mathrm{RE}$ \\
\hline Time-varying Efficiency & 0.889 & 0.890 & 0.981 & 0.816 \\
\hline Std Dev & 0.0459 & 0.0621 & 0.000608 & 0.0353 \\
\hline Persistent Efficiency & 0.985 & 0.847 & 0.974 & 0.965 \\
\hline Std Dev & 0.0551 & 0.0395 & 0.0451 & 0.0864 \\
\hline Overall Efficiency & 0.876 & 0.754 & 0.956 & 0.788 \\
\hline Std Dev & 0.0360 & 0.0608 & 0.0460 & 0.0843 \\
\hline$* * * \mathrm{p}<0.01, * * \mathrm{p}<0.05, * \mathrm{p}<0.1$ & & & & \\
\hline
\end{tabular}

Table 4 Two Stage SFA Estimates for Fertilizers, by type of Energy, with and without price instrument

\begin{tabular}{|l|l|l|l|l|}
\hline VARIABLES & Electricity & Electricity & Fuels & Fuels \\
\hline $\ln E m p$ Log Employment & $0.341^{* * *}$ & $0.333^{* * *}$ & 0.195 & 0.183 \\
\hline $\ln K \quad$ Log Capital & $0.244^{* * *}$ & $0.259^{* * *}$ & 0.0728 & 0.107 \\
\hline $\ln N E M$ Log non-energy Materials & 0.0372 & 0.0373 & 0.208 & 0.186 \\
\hline $\ln Y \quad$ Log Total Value of Shipments & $0.603^{* * *}$ & $0.607^{* * *}$ & $0.565^{* * *}$ & $0.600^{* * *}$ \\
\hline$G E R A T I O$ Self Generation Ratio & $-1.515^{* * *}$ & $-1.543^{* * *}$ & -0.00885 & -0.0526 \\
\hline $\ln P_{N G}$ Log Natural Gas Price & -0.0605 & -0.0696 & $-1.173^{* * *}$ & $-1.302^{* * *}$ \\
\hline $\ln P_{\text {Elec Log Electricity Price }}$ & $-1.411^{* * *}$ & $-1.291^{* * *}$ & $-0.583^{* *}$ & -0.0333 \\
\hline Constant & $-4.177^{* * *}$ & $-3.972^{* * *}$ & 1.045 & 2.373 \\
\hline & & & & \\
\hline Observations & 300 & 300 & 300 & 300 \\
\hline Number of Firms & 200 & 200 & 200 & 200 \\
\hline Model & $\mathrm{RE}$ & $\mathrm{IV}-\mathrm{RE}$ & $\mathrm{RE}$ & $\mathrm{IV}-\mathrm{RE}$ \\
\hline Time-varying Efficiency & 0.987 & 0.885 & 0.968 & 0.783 \\
\hline Std Dev & 0.000363 & 0.0651 & 0.101 & 0.212 \\
\hline Persistent Efficiency & 0.979 & 0.972 & 0.967 & 0.886 \\
\hline Std Dev & 0.0522 & 0.0524 & 0.0739 & 0.254 \\
\hline Overall Efficiency & 0.966 & 0.860 & 0.936 & 0.693 \\
\hline Std Dev & 0.0528 & 0.0469 & 0.0739 & 0.0791 \\
\hline$* * * \mathrm{p}<0.01, * * \mathrm{p}<0.05, * \mathrm{p}<0.1$ & & & & \\
\hline
\end{tabular}


Including capital stock allows us to look at the short and long run effect of scale on energy use. We define the short run elasticity of scale relative to the demand function

$$
\ln E_{j, i, t}=f\left(\ln \lambda_{s} Y_{i, t}, \ln K_{i, t}, \ln \lambda_{s} E m p_{i, t}, \ln \lambda_{s} N E M_{i, t}, \ldots\right)+\varepsilon_{j, i, t}
$$

And long run relative to

$$
\ln E_{j, i, t}=f\left(\ln \lambda_{l} Y_{i, t}, \ln \lambda_{l} K_{i, t}, \ln \lambda_{l} E m p_{i, t}, \ln \lambda_{l} N E M_{i, t}, \ldots\right)+\varepsilon_{j, i, t}
$$

i.e. in the short run only output, employment and non-energy materials are variable and in the long run capital is also variable. The short and long run elasticies are

$$
\begin{aligned}
& \frac{\partial \ln E_{j, i, t}}{\partial \lambda_{s}}=\beta_{Y}+\beta_{E m p}+\beta_{N E M} \\
& \quad \frac{\partial \ln E_{j, i, t}}{\partial \lambda_{l}}=\beta_{K}+\beta_{Y}+\beta_{E m p}+\beta_{N E M}
\end{aligned}
$$

In other words, the long run elasticity of energy with respect to scale as the sum of the estimated coefficients, $\beta_{*}$ for labor, non-energy materials, total value of shipments, and capital stock. This would measure the percentage impact on energy use of a larger plant for a percent change in both variable and fixed inputs and outputs. In the short run, capital is fixed. The short run elasticity is the sum of the coefficients for the variable inputs and output. It may be best thought of as the elasticity of plant utilization, given fixed capital. Table 5 shows that, in the long run, the elasticity of scale is close to, or slightly greater than unity. The values greater than unity may reflect the tendency for energy intensive activities to be located in larger plants. The smaller short run elasticities reflect that as variable inputs and production fall, relative to the fixed capital stock, energy use falls less than proportionally. This is consistent with observations that the energy output ratio tends to rise as plants produce at less than full capacity over the business cycle.

Table 5 Elasticities of Scale with respect to Energy Use

\begin{tabular}{|l|l|l|l|l|}
\hline & Inorganic & Organic & Resins and Plastics & Fertilizer \\
\hline & Electric & \multicolumn{1}{l|}{} \\
\hline Long Run & 1.0051 & 1.1381 & 1.105 & 1.2363 \\
\hline Short Run & 0.6581 & 0.9381 & 0.845 & 0.9773 \\
\hline & Fuel & & \\
\hline Long Run & 1.0537 & 1.0443 & 0.9915 & 1.076 \\
\hline Short Run & 0.7787 & 0.6673 & 0.6165 & 0.969 \\
\hline
\end{tabular}

\section{Efficiency Results - Census of Manufacturing}

This section explores the efficiency estimates from the $\mathrm{CM}$ analysis in more detail, focusing on the estimates from the IV-RE model. The mean and standard deviations for the plant level efficiencies show that the level of efficiency is fairly high and tightly distributed. For electricity, fertilizers have the highest efficiencies, followed by inorganics, resins \& plastics, and organic chemicals; the range is from 0.71 to 0.86 . For fossil fuels resins \& plastics are the most fuel efficient, followed by organics, inorganics and fertilizers; the range is from 0.69 to 0.79 . 
One consideration is whether new plants that enter the industry might be more efficient than their existing counterparts. For example, a new plant can have more advanced technology, but may initially exhibit poor operations management. Over time, with learning, a new plant may become more efficient. We compare the mean time-varying (TV) and persistent (PER) efficiency of new vs existing plants in table 6 . A pattern emerges. In 7 out of 8 sector-energy combination the time varying efficiency of new plants is worse (lower) and statistically significant via a t-test for difference in group means. The exception is fuel use in fertilizer. The pattern is opposite for persistent efficiency, except for fuel use in inorganics. Fewer of these differences are statistically significant. We interpret this as that while new plants may have slight advantages in technology, when they first enter the industry those advantages are not fully realized, i.e. start out with lower time-varying efficiency. Over time this difference in timevarying efficiency goes away, i.e. these plants learn by doing as they become existing plants five years later (the next CM year of the data). This analysis does not explore these dynamics in detail, so this is a hypothesis to examine in future research.

Table 6 Comparison of Efficiency of New vs Existing Plants by sector and energy type

\begin{tabular}{|l|l|l|l|l|l|l|l|l|l|}
\hline & \multicolumn{3}{|l|}{ Inorganic } & \multicolumn{2}{l|}{ Organic } & \multicolumn{2}{l|}{ Resins \& Plastic } & \multicolumn{2}{l|}{ Fertilizers } \\
\hline & & New & Existing & New & Existing & New & Existing & New & Existing \\
\hline Electric & TV & $0.812^{* * *}$ & 0.823 & $0.850^{* * *}$ & 0.860 & $0.867^{* * *}$ & 0.880 & $0.865^{*}$ & 0.873 \\
\hline & PER & $0.971^{*}$ & 0.970 & $0.977^{* * *}$ & 0.965 & 0.979 & 0.978 & 0.974 & 0.971 \\
\hline Fuel & TV & $0.782^{* * *}$ & 0.792 & $0.779^{* * *}$ & 0.800 & $0.796^{* * *}$ & 0.813 & 0.767 & 0.762 \\
\hline & PER & 0.948 & 0.949 & $0.966^{*}$ & 0.962 & $0.965^{*}$ & 0.964 & 0.912 & 0.884 \\
\hline
\end{tabular}

$* * * \mathrm{p}<0.01, * * \mathrm{p}<0.05, * \mathrm{p}<0.1$

The kernel densities for overall efficiency, shown in figures 2 and 3, reveal more about total efficiencies. First, the distributions for fossil efficiency are more tightly clustered than for electricity, but more importantly there are virtually no plants that might be called "highly inefficient"; the left tail is very thin. In addition, there are few plants that are considered $100 \%$ efficient; this puts the mean efficiency estimates into a different light. Mean efficiency ranging from 0.69 to 0.86 might suggest opportunities for average energy reduction by anywhere from 14 to $31 \%$, relative to an absolute efficiency of $100 \%$. Strictly speaking that is true, but the distributions suggest that $100 \%$ efficiency isn't common. Another way to view the overall level of efficiency in each industry would be to compute the reduction in aggregate energy use if all plants were "efficient", i.e. achieve some empirically relevant level of performance other than $100 \%$. Since there are empirically few plants that are $100 \%$ efficient, we define an "efficient plant" as one that performs at the $90^{\text {th }}$ percentile of the corresponding efficiency distribution. We take the plant level energy use and reduce it by the amount needed to put it at the $90^{\text {th }}$ percentile. If the plant is already at the $90^{\text {th }}$ or greater, then the plant is already "efficient." The ratio of the sum of the "efficient" energy consumption to the sum of the actual energy use reflects the potential level of energy use if all plants were efficient. This might reflect policies and programs that achieve improvements at a high level of comparative performance, the $90^{\text {th }}$ percentile, but not perfect performance, $100 \%$ efficiency. This becomes the basis for our comparison of market based vs program based climate policies. 
Panel A of Table 7 shows the potential percent reduction in energy from eliminating inefficiency as measured by one minus the above ratio. The average is about $-9 \%$. This may seem like a small percentage, but since the base level of energy use in this sector is large this is an substantial amount of energy reduction. This result is also consistent with what (Boyd 2016) reports in a meta-analysis of 2 dozen industry case studies; energy intensive sectors have much tighter distributions of estimated efficiency than non-energy intensive sector. It is likely that in competitive industries that produce energy intensive commodities markets will not tolerate as much energy inefficiency.

Table 7 Potential Reduction in Energy Use if All Plants Were Efficient (90th percentile) by sector and energy type

\begin{tabular}{|l|l|l|l|l|}
\hline \multicolumn{5}{|l|}{ Panel A: Percentage Change in Energy Use at Frontier } \\
\hline & Inorganic & Organic & Resins \& Plastic & Fertilizers \\
\hline Electricity & $-7 \%$ & $-14 \%$ & $-13 \%$ & $-4 \%$ \\
\hline Fuels & $-9 \%$ & $-7 \%$ & $-8 \%$ & $-7 \%$ \\
\hline Panel B: Carbon Price (\$/Ton $\mathrm{CO}_{2}$ ) & Achieving Equivalent Reduction \\
\hline & Inorganic & Organic & Resins \& Plastic & Fertilizers \\
\hline Electricity & $\$ 7.36$ & $\$ 18.47$ & $\$ 15.66$ & $\$ 3.50$ \\
\hline Fuels & $\$ 7.24$ & $\$ 4.10$ & $\$ 6.62$ & $\$ 4.63$ \\
\hline
\end{tabular}

Panel B of Table 7 considers an alternative policy instrument designed to achieve an equivalent reduction in energy use as the percentages reported in Panel A. Specifically, the equivalent tax on $\mathrm{CO}_{2}$ emissions is calculated from the parameter estimates in Tables 1-4 evaluated at the US average prices for electricity (\$19.6/MMBtu) and natural gas (\$4.91/MMBtu) in the industrial sector in the most recent 2012 wave of our panel. The formula used to derive the required carbon $\operatorname{tax}(\mathrm{CT})$ for electricity reductions is given by the following:

$\% \Delta=\frac{(\$ 19.6+C T * 0.1667)^{\beta e e}(\$ 4.91+C T * 0.0597)^{\beta_{e f}}}{(\$ 19.6)^{\beta e e}(\$ 4.91)^{\beta_{e f}}}-1$.

The left-hand side of equation (10) is set equal to the energy reductions calculated in Panel A of Table $6, \beta_{\text {ee }}$ and $\beta_{\text {ef }}$ are the own price elasticity for electricity and the cross price elasticity for fuel (from the IV models in Tables 1-4). The fixed parameters 0.1667 and 0.0597 are the $\mathrm{CO}_{2}$ emissions factors (tons $\mathrm{CO}_{2} / \mathrm{MMBtu}$ ) for electricity purchases and natural gas, respectively. ${ }^{12}$ The weighted-average carbon tax is $\$ 9.48$ /ton $\mathrm{CO}_{2}$ which would achieve equivalent reductions in energy use in the chemical sector as compared to requiring all manufacturing plants make efficiency improvements to reach the frontier. To put this number in perspective, the US EPA and the General Accounting Office currently estimate a median value of the social cost of carbon equal to $\$ 31.84$ per ton $\mathrm{CO}_{2}$ or roughly four times the amount of carbon tax required to achieve equivalent energy reductions in comparison to efficiency investment requirements

\footnotetext{
${ }^{12}$ Average US industrial electricity and natural gas prices are from the US EIA's State Energy Data System (SEDS). $\mathrm{CO}_{2}$ emissions factors are calculated from the EPA's Emissions \& Generation Resource Integrated Database (eGRID) for 2012. SEDS data is available for download at the following: https://www.eia.gov/state/seds/ (last accessed January, 2018). eGRID data is available online: https://www.epa.gov/energy/emissions-generation-resourceintegrated-database-egrid (last accessed January, 2018).
} 
(United States Government Interagency Working Group on Social Cost of Carbon 2013, US EPA 2015). These results suggest that a tax on carbon emissions is likely to be preferable to alternative technology mandates for reducing energy use, at least in these energy intensive sectors. 


\section{Electricity Efficiency Distributions by Sector}

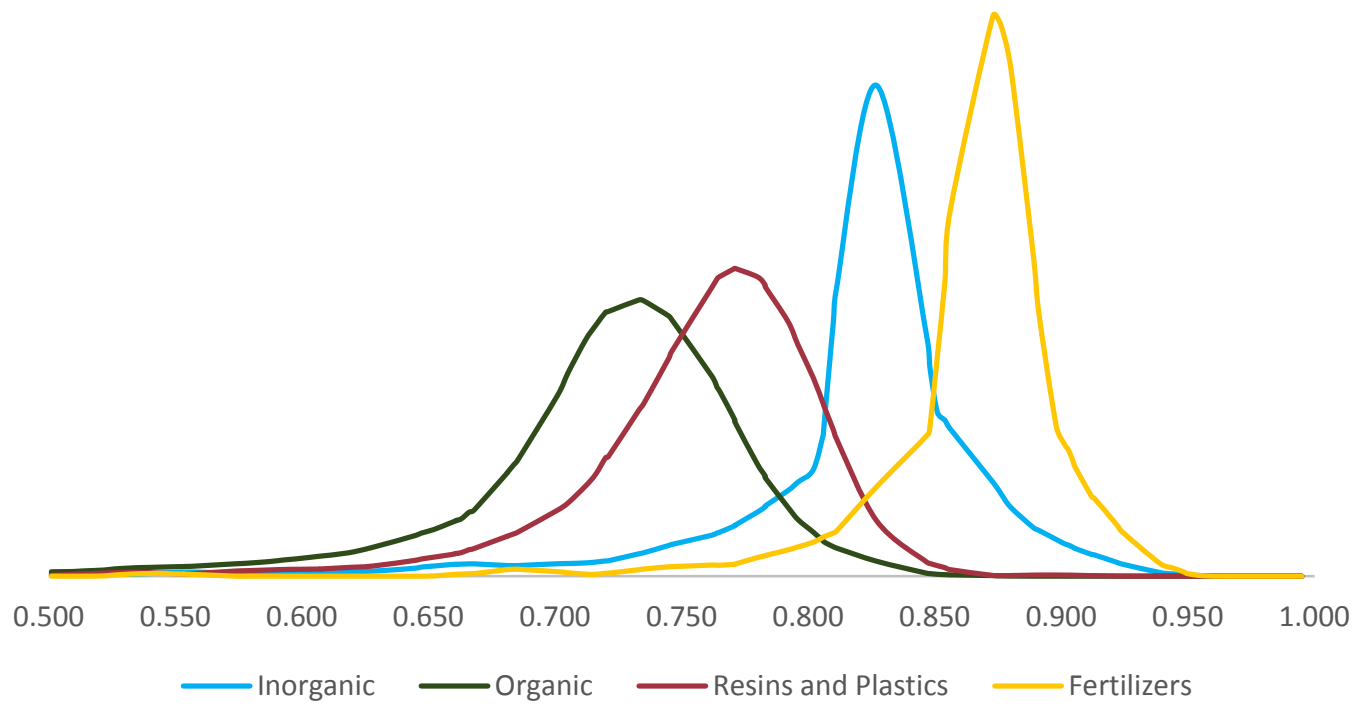

Figure 2 Kernel Density for Plant level Electricity Efficiency by sector

Fossil Fuel Efficiency Distributions by Sector

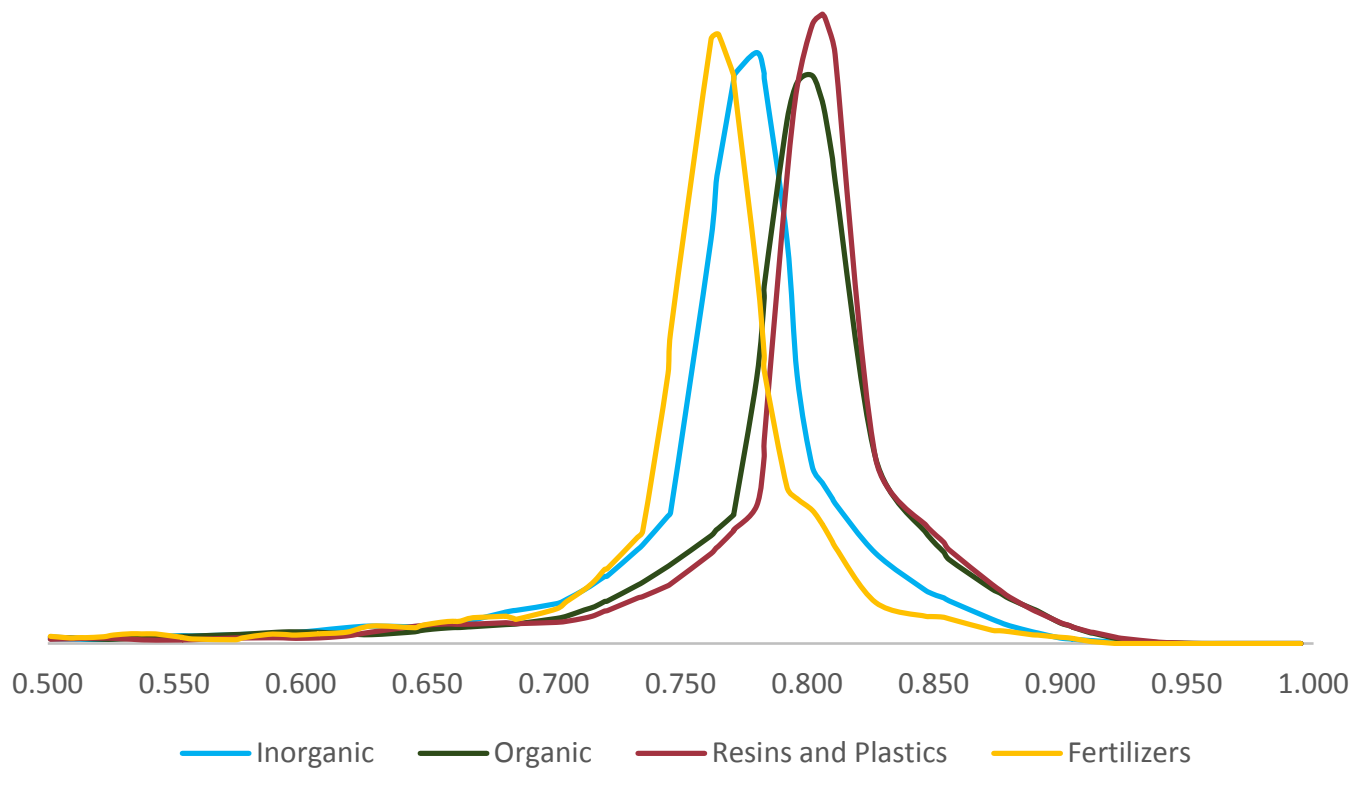

Figure 3 Kernel Density for Plant level Fossil Fuel Efficiency by sector 


\section{MECS Two Stage Parameter Estimates}

We conduct a parallel analysis to that employing the CM data, but using the MECS sample. The major difference is that the MECS data allows us to use plant level fuel and electric prices, with fuel prices begin further broken down into natural gas and all other fuels. The use of plant level fuel prices raises the same price endogeneity issues as the plant level electric prices does in the CM data. The same two-stage estimation strategy is used, but we instrument the plant level energy prices with the corresponding state level prices for electric, natural gas, and other fuels.

Results are shown in table 8-12. The IV models generally result in smaller, but still significant electricity price elasticities; the exception is organics. For natural gas prices the results of the IV is that natural gas elasticities are similar in magnitude but no-longer significant. This suggests that endogeneity is less of an issue for natural gas. Natural gas is a much more national market, with access to pipeline gas markets for large users. The electric market is fragmented and local (plant) level prices possibly subject to more heterogeneity and local influence. Complementarity, i.e. negative cross price elasticities are prevalent in the MECS analysis, but usually not significant in the IV models with the exception of organic chemicals. 
Table 6 Two Stage SFA Estimates for Inorganic Chemicals, by type of Energy, with and without price instrument - MECS data

\begin{tabular}{|l|l|l|l|l|}
\hline VARIABLES & Electricity & Electricity & Fuels & Fuels \\
\hline Log total value of shipments & $0.562^{* * *}$ & $0.593^{* * *}$ & $0.416^{* * *}$ & $0.434^{* * *}$ \\
\hline Log employment & $0.268^{* * *}$ & $0.278^{* * *}$ & $0.503^{* * *}$ & $0.511^{* * *}$ \\
\hline Log non-energy material cost & $-0.162^{* * *}$ & $-0.180^{* * *}$ & 0.0935 & 0.0845 \\
\hline Log capital & $0.264^{* * *}$ & $0.309^{* * *}$ & $0.260^{* * *}$ & $0.255^{* * *}$ \\
\hline Self-Generation Ratio & & & & \\
\hline Log Price of "other" fuels & 0.0235 & 0.0412 & $-0.149^{* * *}$ & $-0.279^{*}$ \\
\hline Log Price of Natural Gas & -0.0726 & 0.270 & $-0.583^{* * *}$ & -0.740 \\
\hline Log Price of Electricity & $-1.321^{* * *}$ & $-1.055^{* * *}$ & -0.000948 & 0.0464 \\
\hline & & & & \\
\hline Observations & 1300 & 1300 & 1300 & 1300 \\
\hline Number of firm & 700 & 700 & 700 & 700 \\
\hline Model & $\mathrm{RE}$ & $\mathrm{IV}-\mathrm{RE}$ & $\mathrm{RE}$ & $\mathrm{IV}-\mathrm{RE}$ \\
\hline Time-varying Efficiency & 0.876 & 0.881 & 0.767 & 0.757 \\
\hline Persistent Efficiency & 0.974 & 0.796 & 0.963 & 0.945 \\
\hline Overall Efficiency & 0.853 & 0.701 & 0.739 & 0.716 \\
\hline$* * * p<0.01, * * p<0.05, * p<0.1$ & & & & \\
\hline
\end{tabular}

Table 7 Two Stage SFA Estimates for Organic Chemicals, by type of Energy, with and without price instrument - MECS data

\begin{tabular}{|l|l|l|l|l|}
\hline VARIABLES & Electricity & Electricity & Fuels & Fuels \\
\hline Log total value of shipments & $0.317^{* * *}$ & $0.322^{* * *}$ & $0.329^{* * *}$ & $0.322^{* * *}$ \\
\hline Log employment & $0.429^{* * *}$ & $0.436^{* * *}$ & $0.384^{* * *}$ & $0.377^{* * *}$ \\
\hline Log non-energy material cost & 0.0306 & 0.0284 & 0.0588 & 0.0584 \\
\hline Log capital & $0.309^{* * *}$ & $0.316^{* * *}$ & $0.357^{* * *}$ & $0.347^{* * *}$ \\
\hline Self-Generation Ratio & & & & \\
\hline Log Price of “other" fuels & 0.0110 & -0.0736 & 0.0927 & -0.0688 \\
\hline Log Price of Natural Gas & $-0.105^{* *}$ & -0.0143 & $-0.480^{* * *}$ & -0.329 \\
\hline Log Price of Electricity & $-0.658^{* * *}$ & $-0.758^{* * *}$ & $-0.630^{* * *}$ & $-0.967^{* * *}$ \\
\hline & & & & \\
\hline Observations & 1100 & 1100 & 1100 & 1100 \\
\hline Number of firm & 600 & 600 & 600 & 600 \\
\hline Model & $\mathrm{RE}$ & $\mathrm{IV}-\mathrm{RE}$ & $\mathrm{RE}$ & $\mathrm{IV}-\mathrm{RE}$ \\
\hline Time-varying Efficiency & 0.991 & 0.920 & 0.978 & 0.798 \\
\hline Persistent Efficiency & 0.974 & 0.973 & 0.962 & 0.960 \\
\hline Overall Efficiency & 0.966 & 0.895 & 0.941 & 0.767 \\
\hline$* * * p<0.01, * * p<0.05, * p<0.1$ & & & & \\
\hline
\end{tabular}


Table 8 Two Stage SFA Estimates for Resins \& Plastics, by type of Energy, with and without price instrument - MECS data

\begin{tabular}{|l|l|l|l|l|}
\hline VARIABLES & Electricity & Electricity & Fuels & Fuels \\
\hline Log total value of shipments & $0.389^{* * *}$ & $0.408^{* * *}$ & $0.418^{* * *}$ & $0.427^{* * *}$ \\
\hline Log employment & $0.330^{* * *}$ & $0.333^{* * *}$ & $0.525^{* * *}$ & $0.521^{* * *}$ \\
\hline Log non-energy material cost & -0.00264 & 0.00276 & 0.106 & $0.112^{*}$ \\
\hline Log capital & $0.358^{* * *}$ & $0.377^{* * *}$ & $0.284^{* *}$ & $0.298^{* *}$ \\
\hline Self-Generation Ratio & & & & \\
\hline Log Price of “other" fuels & -0.0151 & 0.0318 & 0.0117 & 0.0135 \\
\hline Log Price of Natural Gas & -0.0236 & -0.0591 & $-0.202^{* *}$ & -0.231 \\
\hline Log Price of Electricity & $-0.913^{* * *}$ & $-0.642^{* * *}$ & $-0.529^{* * *}$ & -0.333 \\
\hline & & & & \\
\hline Observations & 1300 & 1300 & 1300 & 1300 \\
\hline Number of firm & 500 & 500 & 500 & 500 \\
\hline Model & $\mathrm{RE}$ & $\mathrm{IV}-\mathrm{RE}$ & $\mathrm{RE}$ & $\mathrm{IV}-\mathrm{RE}$ \\
\hline Time-varying Efficiency & 0.913 & 0.913 & 0.788 & 0.763 \\
\hline Persistent Efficiency & 0.807 & 0.785 & 0.956 & 0.952 \\
\hline Overall Efficiency & 0.737 & 0.717 & 0.753 & 0.727 \\
\hline$* * * p<0.01, * * p<0.05, * p<0.1$ & & & & \\
\hline
\end{tabular}

Table 9 Two Stage SFA Estimates for Fertilizers, by type of Energy, with and without price instrument - MECS data

\begin{tabular}{|l|l|l|l|l|}
\hline VARIABLES & Electricity & Electricity & Fuels & Fuels \\
\hline Log total value of shipments & $0.250^{* *}$ & $0.289^{* * *}$ & $0.294^{*}$ & $0.375^{* *}$ \\
\hline Log employment & $0.678^{* * *}$ & $0.714^{* * *}$ & $0.586^{* *}$ & $0.736^{* * *}$ \\
\hline Log non-energy material cost & 0.0723 & 0.0542 & 0.167 & 0.135 \\
\hline Log capital & $0.328^{* * *}$ & $0.358^{* * *}$ & $0.310^{* *}$ & $0.275^{*}$ \\
\hline Self-Generation Ratio & & & & \\
\hline Log Price of “other" fuels & -0.0320 & -0.177 & -0.0448 & 0.146 \\
\hline Log Price of Natural Gas & 0.166 & 0.239 & -0.0499 & 0.463 \\
\hline Log Price of Electricity & $-0.906^{* * *}$ & $-0.562^{* *}$ & $-1.010^{* * *}$ & -0.482 \\
\hline & & & & \\
\hline Observations & 300 & 300 & 300 & 300 \\
\hline Number of firms & 100 & 100 & 100 & 100 \\
\hline Model & $\mathrm{RE}$ & $\mathrm{IV}-\mathrm{RE}$ & $\mathrm{RE}$ & $\mathrm{IV}-\mathrm{RE}$ \\
\hline Time-varying Efficiency & 0.900 & 0.896 & 0.977 & 0.981 \\
\hline Persistent Efficiency & 0.971 & 0.968 & 0.951 & 0.933 \\
\hline Overall Efficiency & 0.874 & 0.866 & 0.929 & 0.914 \\
\hline$* * * p<0.01, * * p<0.05, * p<0.1$ & & & & \\
\hline
\end{tabular}




\section{Summary}

This paper presents estimates of the distribution of energy efficiency and price elasticities in the four major energy using sectors of the upstream, energy-intensive portions of the Chemical Industry. We analyze data from the CM and MECS separately, since these data sources have their own strengths and weaknesses. If we compare the mean efficiency estimates between the two data sets (table 12) the mean fuel efficiency are fairly similar. Electricity efficiency in inorganics and organics and fuel use in fertilizer differ the most. There is no evidence of bias, in the sense that one data source uniformly has higher or lower mean efficiency. None of the mean efficiency differences are particularly large.

The $\mathrm{CM}$ analysis, since it is not a sample, if the preferred source for the aggregate analysis of the potential savings from efficiency, since all plants are included in the data. That analysis shows that the range of efficiency difference is quite narrow and the total savings associated with moving all inefficient plants to the frontier is small in percentage terms, ranging from a low of $4 \%$ to a high of $14 \%$, depending on the sector and energy type. The average is about $9 \%$. The relatively small percentage difference in efficiency is consistent with other studies that find energy intensive sectors e.g. steel, cement, paper, etc. (Boyd and Zhang 2013, Boyd and Guo 2014, Boyd, Doolin et al. 2017) have a much narrower range of efficiency than less energy intensive ones, e.g. metal based durables, auto assembly, etc. (Boyd 2014, Boyd and Lee 2016). We find that new plants have slightly higher persistent efficiency than existing plants, but enter the industry with lower time-varying efficiency. We interpret this as a new plant learning phenomenon, but this analysis doesn't model this explicitly. The results for fertilizers might bear further examination since this sector was the most sensitive to the data source (CM vs MECS) and model specification.

Table 12 Comparison of Mean Efficiency Estimates

\begin{tabular}{|c|c|c|c|c|c|c|c|c|}
\hline & \multicolumn{2}{|c|}{ Inorganic } & \multicolumn{2}{c|}{ Organic } & Resin \& Plastics & \multicolumn{2}{c|}{ Fertilizer } \\
\hline & Electric & Fuel & Electric & Fuel & Electric & Fuel & Electric & Fuel \\
\hline MECS & 0.701 & 0.716 & 0.895 & 0.767 & 0.717 & 0.727 & 0.866 & 0.914 \\
\hline CM & 0.811 & 0.751 & 0.715 & 0.779 & 0.754 & 0.788 & 0.860 & 0.693 \\
\hline
\end{tabular}

When comparing price elasticities, the fuel price elasticities show the least similarity across the data sets. It should be noted that the MECS fertilizer elasticity estimate for fuel use is positive and not significant in the IV model, but negative and significant for the non-IV version. Non-IV estimates for the MECS fuel elasticities might be the preferred estimates for fuels, but not necessarily for electricity due to the aforementioned ability of large energy users to contract lower electricity prices and relative inability to contract lower natural gas prices (where national spot markets determine prices). Recall that the $\mathrm{CM}$ data requires the fuel use to be imputed from fuel expenditures and state average natural gas prices and MECS has more detailed data on physical consumption, but only for a sample of plants. We would expect the two data sources to be the most different for fuel (natural gas) use. Electricity elasticities are more similar for all but fertilizers. All the MESC elasticities are smaller in absolute magnitude. 
Table 13 Comparison of Own Price Elasticity Estimates

\begin{tabular}{|l|l|l|l|l|l|l|l|l|}
\hline & \multicolumn{2}{|l|}{ Inorganic } & \multicolumn{2}{l|}{ Organic } & \multicolumn{2}{l|}{ Resin \& Plastics } & \multicolumn{2}{l|}{ Fertilizer } \\
\hline & Electric & Fuel & Electric & Fuel & Electric & Fuel & Electric & Fuel \\
\hline MECS & -1.055 & -0.740 & -0.758 & -0.329 & -0.642 & -0.231 & -0.562 & 0.463 \\
\hline CM & -1.098 & -1.242 & -0.917 & -1.318 & -0.801 & -1.204 & -1.291 & -1.302 \\
\hline
\end{tabular}

The estimate of the efficiency gap, defined not by $100 \%$ efficiency but by the $90^{\text {th }}$ percentile of the estimated plant efficiency distribution, is relatively small with many of the CM price elasticities near unity results in a rather modest carbon price equivalent to closing the efficiency gap of $\$ 9.48 /$ ton $\mathrm{CO}_{2}$. The MECS analysis does generate lower elasticities, but similar efficiency estimates and the resulting equivalent carbon prices only rise to $\$ 14.01 /$ Ton $\mathrm{CO}_{2}$ (weighted average). Both are far below the social cost of carbon of $\$ 31.84 /$ Ton $\mathrm{CO}_{2}$. While the effectiveness of programs targeting the efficiency gap depend on many things, this analysis suggests that only very modest carbon price would be needed to get similar impacts. If programs are easy to implement or have positive synergies then both might still be pursued, but the modest nature of the tax to generate energy reductions suggest that, at least for this sector, market approaches may be more effective. 


\section{Appendix A: Two Stage SFA estimates without Capital Stock - CM Data}

Table 14 Two Stage SFA Estimates for Inorganic Chemicals, without capital stock, by type of Energy, with and without price instrument - CM data

\begin{tabular}{|l|l|l|l|l|}
\hline VARIABLES & Electricity & Electricity & Fuels & Fuels \\
\hline Log Employment & $0.109^{* * *}$ & $0.107^{* *}$ & $0.345^{* * *}$ & $0.338^{* * *}$ \\
\hline Log Capital & & & & \\
\hline Log non-energy Materials & $-0.332^{* * *}$ & $-0.338^{* * *}$ & 0.0359 & 0.0285 \\
\hline Log Total Value of Shipments & $1.152^{* * *}$ & $1.177^{* * *}$ & $0.620^{* * *}$ & $0.650^{* * *}$ \\
\hline Self-Generation Ratio & $\mathrm{W}$ & $\mathrm{W}$ & $\mathrm{W}$ & $\mathrm{W}$ \\
\hline Log Natural Gas Price & -0.0796 & -0.131 & $-1.201^{* * *}$ & $-1.270^{* * *}$ \\
\hline Log Electricity Price & $-1.402^{* * *}$ & $-1.106^{* * *}$ & $-0.228^{* *}$ & 0.154 \\
\hline Constant & $-2.233^{* * *}$ & $-1.730^{* * *}$ & $3.924^{* * *}$ & $5.131^{* * *}$ \\
\hline Observations & 2500 & 2500 & 2500 & 2500 \\
\hline Number of Firms & 1400 & 1400 & 1400 & 1400 \\
\hline Model & RE & IV-RE & RE & IV-RE \\
\hline Time-varying Efficiency & 0.981 & 0.818 & 0.972 & 0.788 \\
\hline Std Dev & 0.0197 & 0.0275 & 0.0890 & 0.127 \\
\hline Persistent Efficiency & 0.981 & 0.971 & 0.969 & 0.949 \\
\hline Std Dev & 0.0197 & 0.0828 & 0.000914 & 0.123 \\
\hline Overall Efficiency & 0.963 & 0.794 & 0.942 & 0.748 \\
\hline Std Dev & 0.0273 & 0.0821 & 0.0916 & 0.0760 \\
\hline$* * * p<0.01, * * p<0.05, * p<0.1$ W= withheld for disclosure purposes \\
\hline
\end{tabular}

Table 15 Two Stage SFA Estimates for Organic Chemicals, without capital stock, by type of Energy, with and without price instrument - CM data

\begin{tabular}{|l|l|l|l|l|}
\hline VARIABLES & Electricity & Electricity & Fuels & Fuels \\
\hline Log Employment & $0.409^{* * *}$ & $0.418^{* * *}$ & $0.304^{* * *}$ & $0.318^{* * *}$ \\
\hline Log Capital & & & & \\
\hline Log non-energy Materials & $0.0597^{*}$ & $0.0612^{*}$ & $0.169^{* * *}$ & $0.174^{* * *}$ \\
\hline Log Total Value of Shipments & $0.655^{* * *}$ & $0.657^{* * *}$ & $0.552^{* * *}$ & $0.554^{* * *}$ \\
\hline Self Generation Ratio & $\mathrm{W}$ & $\mathrm{W}$ & $\mathrm{W}$ & $\mathrm{W}$ \\
\hline Log Natural Gas Price & -0.0952 & $-0.142^{*}$ & $-1.332^{* * *}$ & $-1.421^{* * *}$ \\
\hline Log Electricity Price & $-1.091^{* * *}$ & $-0.944^{* * *}$ & $-0.656^{* * *}$ & $-0.370^{* *}$ \\
\hline Constant & $-1.826^{* * *}$ & $-1.550^{* * *}$ & $3.231^{* * *}$ & $3.485^{* * *}$ \\
\hline Observations & 2100 & 2100 & 2100 & 2100 \\
\hline Number of Firms & 1200 & 1200 & 1200 & 1200 \\
\hline Model & $\mathrm{RE}$ & $\mathrm{IV}-\mathrm{RE}$ & $\mathrm{RE}$ & $\mathrm{IV}-\mathrm{RE}$ \\
\hline Time-varying Efficiency & 0.866 & 0.856 & 0.979 & 0.792 \\
\hline Std Dev & 0.0432 & 0.101 & 0.000643 & 0.0558 \\
\hline Persistent Efficiency & 0.848 & 0.970 & 0.970 & 0.964 \\
\hline Std Dev & 0.0497 & 0.0702 & 0.0721 & 0.0976 \\
\hline Overall Efficiency & 0.735 & 0.830 & 0.950 & 0.763 \\
\hline Std Dev & 0.0634 & 0.0877 & 0.0736 & 0.0902 \\
\hline$* * * \mathrm{p}<0.01, * * \mathrm{p}<0.05, * \mathrm{p}<0.1$ & $\mathrm{~W}=$ withheld for disclosure purposes \\
\hline
\end{tabular}


Table 16 Two Stage SFA Estimates for Resins and Plastics, without capital stock, by type of Energy, with and without price instrument - CM data

\begin{tabular}{|l|l|l|l|l|}
\hline VARIABLES & Electricity & Electricity & Fuels & Fuels \\
\hline Log Employment & $0.341^{* * *}$ & $0.343^{* * *}$ & 0.0366 & 0.0356 \\
\hline Log Capital & & & & \\
\hline Log non-energy Materials & 0.00669 & 0.0177 & 0.0114 & 0.0362 \\
\hline Log Total Value of Shipments & $0.744^{* * *}$ & $0.746^{* * *}$ & $0.921^{* * *}$ & $0.928^{* * *}$ \\
\hline Self Generation Ratio & $\mathrm{W}$ & $\mathrm{W}$ & $\mathrm{W}$ & $\mathrm{W}$ \\
\hline Log Natural Gas Price & $-0.178^{* * *}$ & $-0.233^{* * *}$ & $-0.892^{* * *}$ & $-1.019^{* * *}$ \\
\hline Log Electricity Price & $-1.006^{* * *}$ & $-0.803^{* * *}$ & $-0.506^{* * *}$ & -0.0197 \\
\hline Constant & $-1.385^{* * *}$ & $-0.872^{* * *}$ & $0.709^{* *}$ & $1.951^{* * *}$ \\
\hline Observations & 2800 & 2800 & 2800 & 2800 \\
\hline Number of Firms & 1600 & 1600 & 1600 & 1600 \\
\hline Model & $\mathrm{RE}$ & $\mathrm{IV}-\mathrm{RE}$ & $\mathrm{RE}$ & $\mathrm{IV}-\mathrm{RE}$ \\
\hline Time-varying Efficiency & 0.881 & 0.875 & 0.980 & 0.806 \\
\hline Std Dev & 0.0469 & 0.0667 & 0.000650 & 0.0849 \\
\hline Persistent Efficiency & 0.985 & 0.979 & 0.973 & 0.964 \\
\hline Std Dev & 0.000457 & 0.0186 & 0.0413 & 0.0838 \\
\hline Overall Efficiency & 0.868 & 0.856 & 0.953 & 0.777 \\
\hline Std Dev & 0.0475 & 0.0673 & 0.0405 & 0.0317 \\
\hline$* * * p<0.01, * * p<0.05, * 0<0.1 \mathrm{~W}=$ withheld for disclosure purposes \\
\hline
\end{tabular}

Table 17 Two Stage SFA Estimates for Fertilizers, without capital stock, by type of Energy, with and without price instrument - CM data

\begin{tabular}{|l|l|l|l|l|}
\hline VARIABLES & Electricity & Electricity & Fuels & Fuels \\
\hline Log Employment & $0.341^{* * *}$ & $0.343^{* * *}$ & 0.0366 & 0.0356 \\
\hline Log Capital & & & & \\
\hline Log non-energy Materials & 0.00669 & 0.0177 & 0.0114 & 0.0362 \\
\hline Log Total Value of Shipments & $0.744^{* * *}$ & $0.746^{* * *}$ & $0.921^{* * *}$ & $0.928^{* * *}$ \\
\hline Self Generation Ratio & $\mathrm{W}$ & $\mathrm{W}$ & $\mathrm{W}$ & $\mathrm{W}$ \\
\hline Log Natural Gas Price & $-0.178^{* * *}$ & $-0.233^{* * *}$ & $-0.892^{* * *}$ & $-1.019^{* * *}$ \\
\hline Log Electricity Price & $-1.006^{* * *}$ & $-0.803^{* * *}$ & $-0.506^{* * *}$ & -0.0197 \\
\hline Constant & $-1.385^{* * *}$ & $-0.872^{* * *}$ & $0.709^{* *}$ & $1.951^{* * *}$ \\
\hline Observations & 2800 & 2800 & 2800 & 2800 \\
\hline Number of Firms & 1600 & 1600 & 1600 & 1600 \\
\hline Model & $\mathrm{RE}$ & $\mathrm{IV}-\mathrm{RE}$ & $\mathrm{RE}$ & $\mathrm{IV}-\mathrm{RE}$ \\
\hline Time-varying Efficiency & 0.881 & 0.875 & 0.980 & 0.806 \\
\hline Std Dev & 0.0469 & 0.0667 & 0.000650 & 0.0849 \\
\hline Persistent Efficiency & 0.985 & 0.979 & 0.973 & 0.964 \\
\hline Std Dev & 0.000457 & 0.0186 & 0.0413 & 0.0838 \\
\hline Overall Efficiency & 0.868 & 0.856 & 0.953 & 0.777 \\
\hline Std Dev & 0.0475 & 0.0673 & 0.0405 & 0.0317 \\
\hline$* * * p<0.01, * * p<0.05, * p<0.1 \mathrm{~W}=$ withheld for disclosure purposes \\
\hline
\end{tabular}




\section{REFERENCES}

Allcott, H. and M. Greenstone (2012). "Is There an Energy Efficiency Gap?" The Journal of Economic Perspectives 26(1): 3-28.

Amsler, C., A. Prokhorov and P. Schmidt (2016). "Endogeneity in stochastic frontier models." Journal of Econometrics 190(2): 280-288.

Bardazzi, R., F. Oropallo and M. G. Pazienza (2015). "Do manufacturing firms react to energy prices? Evidence from Italy." Energy Economics 49: 168-181.

Bartelsman, E. and W. Gray (1996). The NBER Manufacturing Productivit Data Base. Cambridge MA, National Bureau of Economic Research.

Bostian, M., R. Färe, S. Grosskopf and T. Lundgren (2016). "Environmental investment and firm performance: A network approach." Energy Economics 57: 243-255.

Boyd, G., M. Doolin, E. Dutrow and S. Zhang (2017). "A New Benchmark of Energy Performance for Energy Management in U.S. and Canadian Integrated Steel Plants." Iron and Steel Technology(May): 53-61.

Boyd, G. and J. M. Lee (2016). Measuring Plant Level Energy Efficiency and Technical Change in the U.S. Metal-Based Durable Manufacturing Sector Using Stochastic Frontier Analysis, Center for Economic Studies, U.S. Census Bureau.

Boyd, G. and J. M. Lee (2017). Energy Efficiency, Technical Change and Price Responsiveness in Non-Energy Intensive Chemicals Manufacturing.

Boyd, G. and G. Zhang (2013). "Measuring improvement in energy efficiency of the US cement industry with the ENERGY STAR Energy Performance Indicator." Energy Efficiency 6(1): 105-116.

Boyd, G. A. (2008). "Estimating Plant Level Manufacturing Energy Efficiency with Stochastic Frontier Regression." The Energy Journal 29( 2): 23-44.

Boyd, G. A. (2014). "Estimating the changes in the distribution of energy efficiency in the U.S. automobile assembly industry." Energy Economics 42(0): 81-87.

Boyd, G. A. (2016). "Comparing the statistical distributions of energy efficiency in manufacturing: meta-analysis of 24 Case studies to develop industry-specific energy performance indicators (EPI)." Energy Efficiency: 1-22.

Boyd, G. A. and E. M. Curtis (2014). "Evidence of an "Energy-Management Gap" in U.S. manufacturing: Spillovers from firm management practices to energy efficiency." Journal of Environmental Economics and Management 68(3): 463-479. 
Boyd, G. A. and C. Delgado (2012). Measuring Improvement in the Energy Performance of the U.S. Corn Refining Industry. DUKE ENVIRONMENTAL ECONOMICS WORKING PAPER SERIES. Durham NC, NICHOLAS INSTITUTE FOR ENVIRONMENTAL POLICY SOLUTIONS: 1-18.

Boyd, G. A. and Y. Guo (2014). "An Energy Performance Indicator for integrated paper and paperboard mills: A new statistical model helps mills set energy efficiency targets." Paper360 March/April: 26-28.

Chung, Y. H., R. Fare and S. Grosskopf (1997). "Productivity and Undesirable Outputs: A Directional Distance Function Approach." Journal of Environmental Management 51: 229-240.

Davis, S. J., C. Grim, J. Haltiwanger and M. Streitwieser (2012). "Electricity Unit Value Prices and Purchase Quantities: U.S. Manufacturing Plants, 1963-2000." Review of Economics and Statistics 95(4): 1150-1165.

Energy Information Administration (1994). NEMS Industrial Module Documentation Report, U.S. Department of Energy.

Filippini, M. and L. C. Hunt (2011). "Energy Demand and Energy Efficiency in the OECD Countries: A Stochastic Demand Frontier Approach." The Energy Journal 32(2): 59-80.

Filippini, M. and L. C. Hunt (2012). "US residential energy demand and energy efficiency: A stochastic demand frontier approach." Energy Economics 34(5): 1484-1491.

Filippini, M. and L. C. Hunt (2015). "Measurement of energy efficiency based on economic foundations." Energy Economics 52, Supplement 1: S5-S16.

Gerarden, T. D., R. G. Newell and R. N. Stavins (2017). "Assessing the Energy-Efficiency Gap." Journal of Economic Literature 55(4): 1486-1525. Greene, W. H. (2002). Fixed and Random Effects in Stochastic Frontier Models. New York Univesity Economics department working paper.

Huntington, H. (1995). "Been Top Down So Long It Looks Like Bottom Up." Energy.

Jaffe, A. B. and R. N. Stavins (1994). "The energy-efficiency gap What does it mean?" Energy Policy 22(10): 804-810.

Jondrow, J., I. Materov, K. Lovell and P. Schmidt (1982). "On the Estimation of Technical Inefficiency in the Stochastic Frontier Production Function Model." Journal of Econometrics 19(2/3): 233-238.

Kermeli, K., E. Worrell, W. Graus and M. Corsten (2017). Energy Efficiency and Cost Saving Opportunities for Ammonia and Nitrogenous Fertilizer Production An ENERGY STAR ${ }^{\circledR}$ Guide for Energy \& Plant Managers. O. o. A. a. Radiation. 
Kumbhakar, S. C., G. Lien and J. B. Hardaker (2014). "Technical efficiency in competing panel data models: a study of Norwegian grain farming." Journal of Productivity Analysis 41(2): 321337.

Lundgren, T., P.-O. Marklund and S. Zhang (2016). "Industrial energy demand and energy efficiency - Evidence from Sweden." Resource and Energy Economics 43: 130-152.

Lundgren, T. and W. Zhou (2017). "Firm performance and the role of environmental management." Journal of Environmental Management 203(Part 1): 330-341.

Lutz, B. J., P. Massier, K. Sommerfeld and A. Löschel (2017). Drivers of energy efficiency in German manufacturing: A firm-level stochastic frontier analysis. ZEW Discussion Papers. Z. f. E. W. C. f. E. E. Research.

Neelis, M., E. Worrell and E. Masanet (2008). Energy Efficiency Improvement and Cost Saving Opportunities for the Petrochemical Industry An ENERGY STAR ${ }^{\circledR}$ Guide for Energy and Plant Managers, Ernest Orlando Lawrence Berkeley National Laboratory.

Nguyen, S. V. and M. L. Streitwieser (2008). "Capital-Energy Substitution Revisited: New Evidence from Micro Data." Journal of Economic and Social Measurement 33(2-3): 129-153.

U.S. Energy Information Administration (2017). Annual Energy Outlook 2017 with projections to 2050. Washington DC.

United States Government Interagency Working Group on Social Cost of Carbon (2013). Technical Support Document: Technical Update of the Social Cost of Carbon for Regulatory Impact Analysis - under Executive Order 12866. C. o. E. Q. Council of Economic Advisors, Department of Agriculture, Department of Commerce, Department of Energy, Department of Transportation, Environmental Protection Agency, National Economic Council, Office of Management and Budget, Office of Science and Technology and Department of the Treasury. Washington, DC.

US EPA (2015). Regulatory Impact Analysis for the Clean Power Plan Final Rule. O. o. A. Q. P. a. S. a. O. o. A. a. Radiation. Research Triangle Park, NC.

Zhang, S., T. Lundgren and W. Zhou (2016). "Energy efficiency in Swedish industry: A firm-level data envelopment analysis." Energy Economics 55: 42-51. 